\title{
SOLAR AND GEOTHERMAL ENERGY UTILIZATION IN SF-2: A SENSITIVITY ANALYSIS
}

H. Davitian, R. LaSala, and W. Marcuse

April 5, 1977

\section{MASTER}

Prepared for the

OFFICE OF THE ASSISTANT ADMINISTRATOR FOR

SOLAR, GEOTHERMAL, AND ADVANCED ENERGY SYSTEMS

By the

ECONOMIC ANALYSIS DIVISION

DEPARTMENT OF ENERGY AND ENVIRONMENT

BROOKHAVEN NATIONAL LABORATORY ASSOCIATED UNIVERSITIES, INC.

UNDER CONTRACT NO. EY-76-C-02-0016 WITH THE

UNITED STATES DEPARTMENT OF ENERGY 


\section{DISCLAIMER}

This report was prepared as an account of work sponsored by an agency of the United States Government. Neither the United States Government nor any agency Thereof, nor any of their employees, makes any warranty, express or implied, or assumes any legal liability or responsibility for the accuracy, completeness, or usefulness of any information, apparatus, product, or process disclosed, or represents that its use would not infringe privately owned rights. Reference herein to any specific commercial product, process, or service by trade name, trademark, manufacturer, or otherwise does not necessarily constitute or imply its endorsement, recommendation, or favoring by the United States Government or any agency thereof. The views and opinions of authors expressed herein do not necessarily state or reflect those of the United States Government or any agency thereof. 


\section{DISCLAIMER}

Portions of this document may be illegible in electronic image products. Images are produced from the best available original document. 


\title{
SOLAR AND GEOTHERMAL ENERGY UTILIZATION IN SF-2: A SENSITIVITY ANALYSIS
}

\author{
H. Davitian, R. LaSala, and W. Marcuse
}

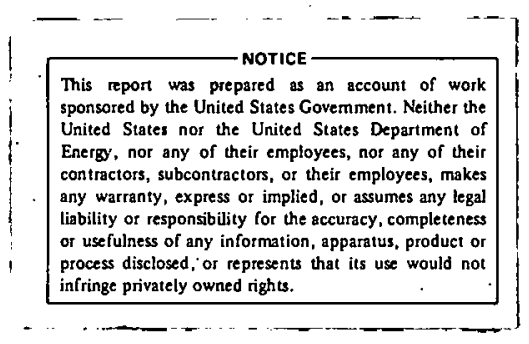

April 5, 1977

*Office of Plans, Budgets and Program Implementation, U.S. Energy Research and Development Administration, Washington, D.C.

Prepared for the

OFFICE OF THE ASSISTANT ADMINISTRATOR

SOLAR; GEOTHERMAL, AND ADVANCED ENERGY SYSTEMS

By the

ECONOMIC ANALYSIS DIVISION

DEPARTMENT OF ENERGY AND ENVIRONMENT 


\title{
"The Department of Energy (DOE) is the successor to the Energy Research and Development Administration (ERDA) and all references to ERDA herein shall be deemed to refer to DOE."
}

\author{
NOT I C E
}

This report was prepared as an account of work sponsored by the United States Government. Neither the United States nor the United States Department of Energy (DOE), nor any of their employees; nor any of their contractors, subcontractors, or their employees, makes any warranty, express or implied, or assumes any legal liability or responsibility for the accuracy, completeness or usefulness of any information, apparatus, product or process disclosed, or represents that its use would not infringe privately owned rights.

Printed in the United States of America Available from

National Technical Information Service

U.S. Department of Commerce 5285 Port Royal Road Springfield, VA 22161

Price: Printed Copy $\$ 4.50$; Microfiche $\$ 3.00$ 


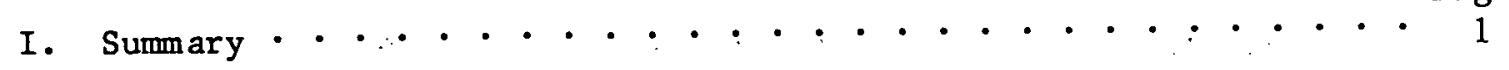

II. Approach . . . . . . . . . . . . . . . . . . . 2

III. Sensitivity Analysis of Criteria. . . . . . . . . . . . . . 3

A. The $\mathrm{SF}-2$ Forecast and the Use of Indices. . . . . . . 3

B. Modification to SF-2 for this Analysis. . . . . . . . 3

C. Discussion of Result.s. . . . . . . . . . . . . . 4

IV. Sensitivity Analysis of Selected Parameters . . . . . . . . . 11

A. Background. . . . . . . . . . . . . . . . . 11

B. ASGA Technological and Economic Parameter Changes . . . . 11

C. Results. . . . ............. . . . . 12

v. Conclusion .. . . . . . . . . . . . . . . . . . . 19 
Deviations of Indices for $\mathrm{SF}-2$ and Base Cases. . . . . . from Minimum Values

Sensitivity of Solar and Geothermal Contributions. . . . . 6 to Various Levels of Constraint on Cost, Environmental and Resource Indices

Comparison of SF-2 with Case in which Indices . . . . . . 7 Limited to 1.08 Times Minima

Resource and Electric Generation Statistics. . . . . . 8

Comparison of ASGA Technologies and Alternative . . . . . 9 Fuels in End Use Applications

Elasticity of Solar and Geothermal Utilization . . . . . 10 with Respect to Acceptability Criteria

Comparison of Revised Parameters with SF-2 Values. . . . . 1.l

Comparison of Revised Upper Bounds on Solar and. . . . . . . 12 Geotherma1 Technologies with SF-2 Levels

Comparison of Revised Parameter Case with SF-2, . . . . . . 14 Base and Revised Bound Cases

Marginal Values and Del Costs for Solar and . . . . . 15 Geothermal Technologies in Revised Parameter Case

Effect of Parametric Variations on Solar and Geothermal: . . 17 Utilization and Energy System Indices

Effect of Parametric Variations on Resource Use and. . . . 18 Electricity Generation 


\section{SUMMARY}

This paper reports the results of a study conducted by the National Center for Analysis of Energy Systems for the office of the Assistant Administrator for Solar, Geothermal and Advanced Energy Systems (ASGA) of the Energy Research and Development Administration (ERDA). The purpose of the study was to conduct: a sensitivity analysis of the utilization levels for ASGA technologies during the 1985-2000 time period that were selected by the office of the Assistant

Administrator for Planning and Evaluation (APAE) for the ERDA 77-1 plan. In particular, the sensitivity of the utilization levels was tested with respect to both analytical techniques and to specific parameter assumptions. The sensitivity to analytical techniques was examined insofar as certain criteria, used by APAE to judge the overall "optimality" of alternative scenario possibilities, were examined to elucidate their importance in determining the level of use of the ASGA technologies. The criteria incorporated consideration of such factors as total cost of the energy system, environmental impacts, and resource use patterns. The parameter assumptions studied included costs of ASGA technologies, costs of non-renewable resources and 1 imitations on the use of technologies and resources. To the greatest extent possible, the analytical procedures employed were jdentical to those used by APAE in developing the 77-1 forecasts. As a basis for this sensitivity analysis, the "SF-2" forecast for the year 2000 was chosen.

The main conclusions that emerge from this study are:

1. The implementation levels for ASGA technologies in the year. $2000 \mathrm{can}$ be increased substantially, consistent with criteria employed by APAE in developing the SF-2 forecast.

2. The primary factor limiting the greater implementation of ASGA technologies when analyzed from the perspective of APAE's criteria is the limitation on the allowable level of the total capital cost of the energy system.

3. As the criteria are relaxed slightly to permit greater implementation levels of ASGA technologies, the following trends are observed:

a) there is a significant (about $15 \%$ ) reduction in total electricity generated as decentralized solar technologies substitute for electricity from central station plants;

b) there is a pronounced shift from nuclear to coal-based generation of electricity in order to satisfy limitations that were applied to total capital cost of the energy sector.

4. The use of revised cost and implementation limit parameters, which were developed in an ASGA review of parameter assumptions, resulted in a $40 \%$ increase in solar and geothermal technology use over the levels in $\mathrm{SF}-2 . *$ Solar space heating, solar water heating and geothermal

\footnotetext{
*However, note that the new utilization level is five times ( 4.3 quad) greater than the economically optimum utilization level of solar and geothermal technologies given SF-2 parameter assumptions. The levels of solar and geothermal technologies in SF-2 were exogenously determined. These levels were not necessarily economically optimal. The statement regarding economic optimality refers to a "Base" case described in the report in which the levels of these technologies was determined by the model in a cost minimizing run.
} 
respectively; their use is sensitive to parametric variations. Solar electricity (thermal electric conversion), given the technological and economic characteristics assumed in this study, is not competitive with other intermediate cycle electricity generating systems even under the most favorable parameter variations considered.

\title{
II. APPROACH
}

The scenarios presented in the National Energy RD\&D Plan, ERDA 77-1 and associated documents include limited amounts of energy from ASGA systems in the U.S. energy system in the year 2000. Most of these applications were identified as non-economic; following a multi-objective analysis of the future U.S. energy use, small amounts of ASGA systems were included despite the fact that in some cases alternatives were economically less costly. The work presented here was performed to address the following questions:

1. To what extent can greater utilization of ASGA technologies in the year 2000 be justified on grounds consistent with criteria used as guidelines in developing the SF-2 scenario?

2. What is the effect of varying assumptions regarding the costs and availabilities of ASGA technologies and of non-renewable resources?

Intuition suggests that if ASGA systems are substituted for other systems in a given baseline scenario, then, relative to the baseline one expects that:

1) exhaustible resource use decreases

2) environmental effects decrease

3) system costs increase

4) capital investment requirements increase.

At some point, increases in system cost, capital cost, etc., become so 1 arge as to render further substitutions of ASGA energy technologies unacceptable. However, it may be possible for most if not all of the substitute technologies to be utilized up to their limits* before that point is reached. The first part of this analysis tested the extent to which such substitutions took place under varying assumptions regarding maximum acceptable increases in certain cost, non-renewable resource and environmental indices. In the second part of the study, cost and availability parameters were varied to determine their effects on the use of ASGA technologies.

The solar and geothermal energy conversion technologies considered in this study are:

\author{
Geothermal Electricity Generation \\ Geothermal Process Heat \\ Solar Electricity Generation \\ (primarily windpower) \\ Solar Process Heat \\ Solar Space Heating \\ Solar Air Conditioning \\ Solar Water Heating
}

"These "limits" are estimated on the base of resource limitations, or on limitations on market saturation - on market penetration rates. 
Biomass conversion, photovoltaics, methane from geopressured resources, and ocean thermal gradient energy conversion technologies were not included in this study.

\section{SENSITIVITY ANALYSIS OF CRITERIA}

Forecast and the Use of Indices

The baseline scenario chosen for the analysis is SF-2, the principal forecast established by APAE for ERDA 7.7-1.1 As part of the process of developing this scenario, APAE employed a set of indices of cost, environmental effects, and resources ${ }^{2}$ and ran the Brookhaven Energy System Optimization Model (BESOM) ${ }^{3}$ a number of times to separately minimize the value of each of these indices. 4 From these runs, trade-offs among costs, environmental effects and resource requirements could be inferred. Based on this information, APAE selected a compromise scenario judged to most closely approach all of the first six minima shown in Appendix 4, plus a minimum level of oil imports. Also from these runs, APAE identified technologies such as solar direct thermal and. synthetic fuels which satisfied criteria other than least cost.

The forecast that emerged as SF-2 evolved as a compromise scenario and deviated further from the theoretical model solution to incorporate factors not implicitly represented in BESOM. Minimum levels of the non-economic, but "desirable," technologies noted earlier were forced into the forecast. Gas steam electrical generators were phased out over the forecast period rather.than being abruptly terminated prior to 1985 to reflect the reality of reported utility plans. Retrofit rates of oil furnaces in residences were reduced to be consistent with sector growth rates and economic 1 ifetimes of the hardware. to be replaced. After the exogenous factors were included, the forecast called "SF$2^{\prime \prime}$ resulted.

The scenario that finally emerged as SF-2 is a tightly constrained case which exogenously determines the contributions from non-economic synthetic fuels and ASGA technologies. The open-ended supplies are imported oil, coal for direct use, and coal steam electricity generation.

Modification to SF-2 for this Analysis

The criteria employed in the present analysis to determine the acceptability of various levels of ASGA technology contributions were the levels of the previously described indices used by APAE. Of special interest in judging a particular scenario are four key indices: total annualized system cost; total capital cost of the energy system; a weighted, composite environmental index; and total resource use. In order to compute the deviations in the

1. See Appendix 1 for a description of this scenario including certain fuel and technology prices used as inputs and the resource and conversion. technology utilization levels resulting in this scenario.

2. See Appendix 2 for a description of the indices.

3. See Appendix 3 for a description of the BESOM model.

4. See Appendix 4 for the results of the minimization runs. 
indices associated with the introduction of ASGA energy technologies, it was necessary to make several modifications to the model. First, the upper and lower bounds on the amounts of certain supplies and demands were changed to permit the inclusion of higher levels of solar and geothermal technologies.* Oil imports were 1 imited to not more than 21.9 quads in order not to exceed the $S F-2$ level of oil imports. With these modifications, the BESOM model was run to minimize total annual system cost as the objective. The values of indices for this case (designated the "Base" Case) were not substantially different from those obtained in the final constrained SF-2 run as can be seen in Table 1; in fact, all indices but two in the Base Case are closer to their respective minima than they are in SF-2. Similarly the resource mix in the Base Case is quite similar to $\mathrm{SF}-2$ in most respects with a few key exceptions.

In the Base Case, neither solar electric nor geothermal electric supply conversion technologies entered the solution; only 1.34 quads of direct use ASGA technology contributions are employed. Only 0.5 quads of the 4.90 quads of ASGA technologies forced into SF-2 would have entered competitively** and the additional .84 quads competitively entering the Base Case results from freeing constraints that limit solar utilization as described in Appendix 5.

Having established that the above modifications did not have significant impacts on the output of the model, other changes were made: A new set of constraints were imposed which specified that the values attained by each of the indices could not exceed their respective minima by more than given percentages. This assured that the resultant solutions would be "acceptable" where

acceptability was defined by the maximum permissible index deviations. Also, a new objective function was specified; namely, to introduce into the solution as much ASGA energy as possible (without conflicting with the acceptability or any other constraints). Finally, the upper bounds on the ASGA technology contributions were increased in accordance with ASGA specifications. These changes made it possible to quickly and easily determine the relationship between the level of ASGA technology utilization and the values of the energy system indices.

\section{Discussion of Results}

(a) Relationship between ASGA Inputs and Deviations in Indices. The basic results of this analysis regarding the variation in ASGA inputs to changes in the amount of deviation permitted in the indices from their minima are shown in Table 2. The values of the eight indices and the energy contributions from ASGA technologies are tabulated for five cases with varying levels of permitted deviations of the indices from their minimum values (constraint levels). The minimal values for the indices, the maximum allowable energy contributions from each ASGA technology (as specified by ASGA) and the statistics for SF-2 are shown for reference. In addition, the percentage deviation of all indices from

*See Appendix 5 for a more detailed description of the changes.

**As determined by examining the sign of the marginal values for these technologies in the SF-2 solution. 
Table 1

DEVIATIONS OF INDICES FOR SF-2 AND BASE CASES FROM MINIMUM VALUES

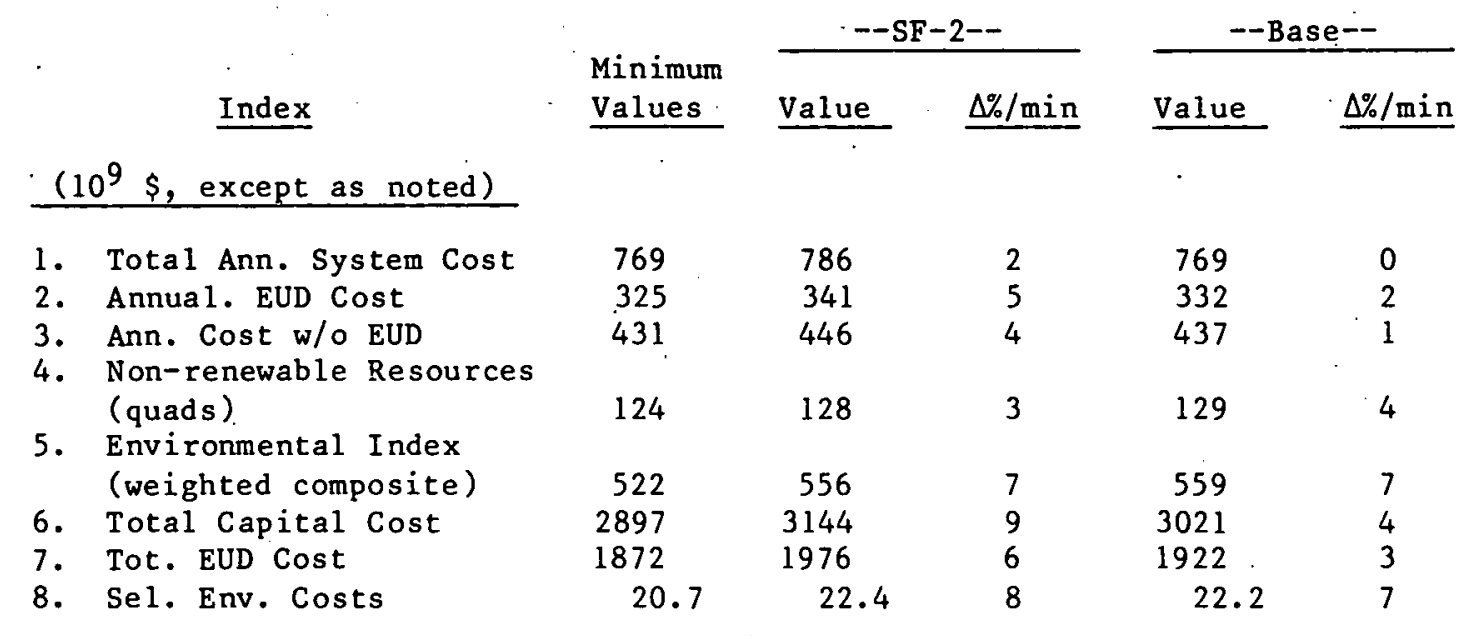

the indices from the minimum values and the fractional utilization of ASGA technologies relative to the maximum allowable levels are shown.*

As the constraints on the indices are relaxed (i.e., as the constraint level increases) greater amounts of ASGA technology inputs are observed as expected. These inputs range from 3.78 quads for the most constrained case that provided a feasible solution (th 1.04 constraint level) to 9.4 quads in the least constrained ( 1.14 constraint level) case. As a basis for comparison, the SF-2 level of ASGA inputs was 4.90 quads. With regard to the four key indices, the total annualized system cost is essentially unchanged from SF-2 levels in all cases, the non-renewable resource requirements are about $8 \%$ less than SF-2 levels in all cases except the 1.04 constraint leve1, and the environmental. and total capital cost indices generally rise with increasing ASGA technology implementation. The surprising rise in the environmental index (as much as $9 \%$ above SF-2 levels) is found to result from the need to use more coal (to limit the rise in total capital costs) as ASGA technology implementation levels rise and is discussed in more detail below.

The general character of the results that emerges from Table 2 can be described as follows: Substantial increases in ASGA technology contributions are observed even if only relatively small deviations are permitted in indices employed by APAE as criteria for judging future energy scenarios. In the 1.08 constraint level case, a $66 \%$ increase in total ASGA technology inputs is experienced with reductions in all four key indices from SF-2 levels. These particular results are summarized in Table 3. The highest total ASGA inputs observed in these cases, 9.4 quads, is nearly twice that employed in SF-2 and

*It is important to note that the absolute minima are obtained using the APAE, not the ASGA, upper bounds on the maximum allowable contributions for each of the solar and geothermal technologies; hence, negative $\Delta \% / \mathrm{min}$ are possible in Table 2 . 
Table 2

Sensitivity of Solar and Geothermal Contributions to Varlous Levels of Constraint on Cost, Environmental and Resource Indices

Trital U.S. Energy Systen, Year 2000, Winter Peaking System

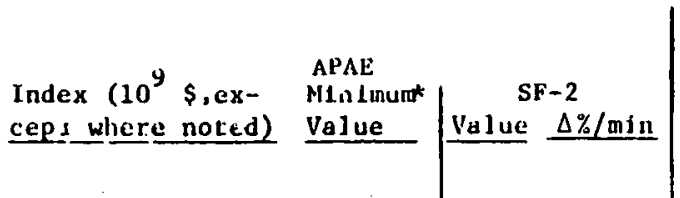

\begin{tabular}{|c|c|c|c|c|c|c|c|c|c|c|c|}
\hline \multicolumn{2}{|c|}{ 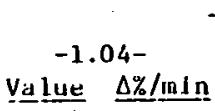 } & $\begin{array}{r}\text { Constra } \\
-1.0 \\
\text { Value }\end{array}$ & $\begin{array}{l}\text { Int Leve } \\
6- \\
\Delta \% / \mathrm{m} \mathrm{in} \\
\end{array}$ & $\begin{array}{c}-1 . \\
\text { value }\end{array}$ & $\begin{array}{l}08- \\
\Delta \% / m 1 n\end{array}$ & $\begin{array}{c}-1 . \\
\text { Value }\end{array}$ & $\begin{array}{l}10- \\
\Delta \% / \mathrm{mLn}\end{array}$ & $\underline{\text { Value }}^{-1}$ & $\begin{array}{l}12- \\
\Delta x / \mathrm{mln}\end{array}$ & $\underline{\text { Value }}^{-1}$ & $\begin{array}{l}14- \\
\Delta \% / \mathrm{mln}\end{array}$ \\
\hline 783 & 2 & 774 & 1 & 778 & 1 & 781 & 2 & 786 & 2 & 791 & 3 \\
\hline 344 & 3 & 342 & 5 & 348 & 7 & 354 & 9 & 360 & 11. & 366 & 13 \\
\hline 449 & 4 (B) & 432 & 0 & 430 & 0 & 427 & -1 & 426 & -1 & 425 & -2 \\
\hline 128 & 3 & 121 & -3 & 119 & -5 & 118 & -5 & 117 & -6 & 117 & -6 \\
\hline 538 & 3 & 535 & 2 & 550 & 5 & 564 & 8 & 581 & 11 & 595 & 14 (B) \\
\hline 3013 & 4 (B) & 3071 & $6(B)$ & 3129 & 8 (B) & 3187 & $10(B)$ & 3245 & 12 (B) & 3303 & 14 (B) \\
\hline 1932 & 3 & 1984 & $6(B)$ & 2022 & 8 (B) & 2059 & 10 (B) & 2097 & 12 (B) & 2134 & 14 (B) \\
\hline 21.5 & 4 (B) & 21.9 & $6(B)$ & 22.4 & $8(B)$ & 23.8 & $10(B)$ & 23.2 & 12 (B) & 23.4 & 13 \\
\hline & $\% / \max$ & & $\underline{q / \max }:$ & & $\% / \max$ & & $\% / \max$ & & $\% / \max$ & & $x / \operatorname{mox}$ \\
\hline 2.2 & 73 & 3.00 & 100 & 3.00 & 100 & 3.00 & 100 & 3.00 & 100 & 3.00 & 100 \\
\hline 1.0 & 100 & 1.00 & J00 & 1.00 & 100 & 1.00 & 100 & 1.00 & 100 & 1.00 & 1.00 \\
\hline 0 & o & 2.00 & 100 & 2.00 & 100 & 2.00 & 100 & 2.00 & 100 & 2.00 & 100 \\
\hline 0 & 0 & .83 & 27 & 1.25 & 42 & 1.37 & 46 & 1.76 & 59 & 2.13 & 71 \\
\hline 0 & 0 & 0 & 0 & .05 & 3 & .24 & 12 & .24 & 12 & .24 & 1.2 \\
\hline 0 & 0 & 0 & 0 & .26 & 74 & .35 & 100 & .35 & 100 & .35 & 100 \\
\hline .53 & 76 & .55 & 78 & .40 & 57 & .48 & 69 & .57 & 81. & .68 & 97 \\
\hline 3.73 & 31 & 7.39 & 61 & 7.96 & 66 & 8.44 & 70 & 8.92 & 74 & 9.40 & 78 \\
\hline
\end{tabular}

1. Ann. Total. System 769 rost

2. Annualfzed EUD Cost 325

3. Cost w/o EUUD

431

$\therefore \quad \begin{aligned} & \text { Non-renewable } \\ & \text { Kesources(10 }\end{aligned}$

5. Ewvำ

6. Total Capti. Cost 2897

7. Total (illi) Capltal $1872 \quad 1.976$

8. Sel. linv. Cost

ASCiA Technoloriest ASCa

Geo. El Allowable

Geo. Prucess lleat.

Solar Electrictey**

Solar Process lluat

Sular Space lleat

Solar A/C.

Solar Water Heat TOIAI.

\begin{tabular}{r|rr}
3.00 & 3.00 & 100 \\
1.00 & .50 & 50 \\
2.00 & .29 & 15 \\
3.00 & .34 & 11 \\
1.95 & .50 & 26 \\
.35 & .09 & 26 \\
.70 & .18 & 26 \\
12.00 & 4.90 & 41
\end{tabular}

*Minimizations are with ASCA technologies linitcul to APAE's SF-2 maximum values

* Energy tlow measured as thermal Input to power plants. All others as inputs to end use device.

TAStiA teclinology levels in SF-2 were excgenously deternibed. The maxlmum allowable statistlcs do not apply to the SF-2 case.

Note: "( $(B) "$ Indicates that lindex is binding (e.g. at the constralnt level). 
Table 3

COMPARISON OF SF-2 WITH CASE' IN WHICH INDICES LIMITED TO 1.08 TIMES MINIMA:

\author{
Total Ann. System Cost \\ Annualized EUD Cost \\ Ann. Cost w/o EUD \\ Total Capital Cost \\ Total EUD Cost \\ Sel. Env. Cost \\ ASGA Technology (Quads) \\ Geothermal Electricity \\ Geothermal Process heat \\ Solar Electricity \\ Solar Process Heat \\ Solar Space Heat \\ Solar A/C \\ Solar Water Heat
}

Index $\left(10^{9}\right.$ s except as noted $)$

Non-Renewable Resources (quads)

Environmental Index (weighted composite)

Tota1 ASGA Inputs

$S F-2$
786
341
446
128
556
3144
1976
22.4

3.00

.50

.29

.34

.50

.09

.18

4.90
1.08 Constraint Leve 1

Value $\quad \Delta \% / \mathrm{SF}-2$

778
348
430
119
550
3129
2022
22.

$-1$

2

$-4$

$-7$

$-1$

0

2

0

about $80 \%$ of the maximum allowable (only the space heating application is not implemented at the ASGA maximum permitted level).*

(b) Reduction in Resources and Electricity Generated Associated with Increased ASGA Inputs. One of the main consequences of increasing levels of ASGA inputs is to reduce the amount of electricity generated. As shown in Table 4, electricity generation drops as much as $16 \%$ below SF-2 levels. Sectors showing no changes are not detailed in Table 4; the statistics for such sectors are included in Appendix 4. The detailed shifts from alternative fuels (including and, in fact, primarily electricity) to ASGA technologies at the end use applications that underlie this reduction in the dependence upon electricity are shown in Table 5 .

Non-renewable. resource usage (fossil plus nuclear) drops about $8 \%$ from SF-2 levels in all cases except for the 1.04 constraint level case.

(c) Capital Cost and Environmental Constraints. The total system capital cost is the index that plays the primary role in limiting the implementation of ASGA technologies. From Table 2, it is seen that total capital cost binds in every case. This is not an unexpected result since, in general, ASGA

*Remember that biomass, conversion, phtotvoltaic conversion, geopressured methance, and ocean termal gradient energy conversion technologies were not included in this analysis. 
Table 4

\section{Resource and Electric Generation Statistics}

Note: only those resource and electric generation sectors indicating changes from $\mathrm{SF}-2$ are shown

Units: Quads per year

Constraint Levels

\section{Resources}

Non-Renewable:

Coal

Nuclear

TOTAL $^{*}$

Renewable $e^{* *}$
Geothermal
Solar
TOTAL

Electric Generation

Coal

Nuclear

Geothermal

Solar

TOTAL +
$\mathrm{SF}-2 \quad$ Base

$-1.04-\quad-1.06-\quad-1.08=-1.10-\quad-1.12-\quad-1.14-$

$\begin{array}{rrrrrrrr}31.7 & 33.7 & 31.7 & 27.7 & 30.5 & 33.5 & 38.3 & 43.0 \\ 28.8 & 27.7 & 29.1 & 29.1 & 21.5 & 17.7 & 11.8 & 6.5 \\ 128.1 & 128.7 & 128.1 & 121.1 & 119.3 & 118.5 & 117.4 & 116.6\end{array}$

$\begin{array}{rrrrrrrr}3.5 & .50 & 3.2 & 4.0 & 4.0 & 4.0 & 4.0 & 4.0 \\ 1.4 & .84 & .5 & 3.4 & 4.0 & 4.0 & 4.9 & 5.4 \\ 4.9 & 1.34 & 3.7 & 7.4 & 8.0 & 8.4 & 8.9 & 9.4\end{array}$

\footnotetext{
*Includes natural gas, oil (domestic and imported), and shale

* Renewable resources measured as thermal inputs (i.e., oil equivalent thermal inputs for electric generation and thermal inputs to end use devices for direct applications)

tIncludes oil steam, gas steam, gas turbine inputs, hydro.
} 
Table 5 .

Comparison of ASGA Technologies and Alternative Fuels in End Use Applications

Energy Use in End Use Sector (Quads)

End Use Sector and Fuel Used

$\mathrm{SF}-$

Bas

1.04

1.06

1.08

1.10

1.12

1.14

Process Heat

ASGA

. Electric

Gas

oil

Coal

$\begin{array}{rrr}.84 & .84 & 1.00 \\ 1.90 & .89 & 1.80 \\ 6.80 & 7.16 & 6.97 \\ 5.62 & 5.62 & 5.62 \\ 8.50 & 8.50 & 7.25\end{array}$

1.83

2.25

2.37

2.76

3.13

7.04

6.42

6.24

6.03

6.03

8.50

5.62

5.62

5.62

5.62

5.62

Space Heat.

Solar

Electric

Heat Pump

Gas

oil

Other

$\begin{array}{rr}.50 & .50 \\ 1.78 & 1.78 \\ .44 & .44 \\ 5.79 & 5.79 \\ 4.56 & 4.56 \\ .55 & .55\end{array}$

0
1.78

8.50

8.50

8.50

8.16

7.66

Air Conditioning
Solar
Electric
Gas
Other

$\begin{array}{cccccccc}0.09 & 0 & 0 & 0 & .26 & .35 & .35 & .35 \\ 1.21 & 1.14 & 1.13 & 1.13 & 1.04 & .97 & .97 & .97 \\ .03 & .03 & .03 & .03 & .03 & .03 & .03 & .03 \\ 0 & .20 & 0 & .21 & .24 & .34 & .34 & .34\end{array}$

Water Heating
Solar
Electric
Gas
Oil

$\begin{array}{rrrrrrrr}.18 & 0 & .53 & .55 & .40 & .48 & .57 & .68 \\ 1.50 & 1.50 & 1.50 & 1.50 & 1.50 & 1.32 & 1.10 & 1.00 \\ 1.19 & .85 & .55 & .47 & .79 & .98 & 1.19 & 1.19 \\ .10 & .68 & .11 & .14 & .10 & .10 & .10 & .10\end{array}$

technologies have higher capital, but lower operating, costs than alternative technologies relying on conventional fuels. In addition to 1 imiting the implementation levels of ASGA technologies, the binding of the capital constraint has a second, unexpected effect. The surprising increase in the environmental index for these runs from SF-2 levels results indirectly from the capital constraint: Given the objective of maximizing ASGA inputs and the limitations on capital, the model seeks technology substitutions which can free capital for purchase of ASGA technologies while satisfying the fixed final energy demands. These substitutions may entail small increases in certain indices (such as total annualized system cost) that are nevertheless acceptable because they are within the constraint levels set for that case. One of the most important such substitutions is the replacement of nuclear electricity.generation by coal which occurs because coal plants require less capital investment than nuclear plants. This substitution is detailed for all cases in Table 4 and Figure 1 . Compared to the nuclear to coal 
electricity generation ratio of roughly 2 in $\mathrm{SF}-2$, the ratio in the cases deve1oped here ranges from 1.6 in the 1.04 constraint level case down to 0.22 for the least constrained case. It should be noted that the nuclear electricity level in the 1.14 case may be unrealistic since it is lower than the expected 1985 level of nuclear electricity capacity most of which is in place or under construction. An important consequence of this substitution from nuclear to coal is to increase the level of environmental pollution which is reflected in increases in the environmental index. The constraint level applied in each case limits the degree to which the environmental index can increase which, in all cases limits the amount of nuclear to coal substitution.

(d) Sensitivity of Solution to Index Deviations. The "shadow prices" associated with linear programing solutions provide useful quantitative information for evaluating the relative importance of constraints. With a few algebraic manipulations, the shadow prices can be converted to elasticities of the optimal value of the objective function with respect to the constraining values in question. Of particular interest in this case are the elasticities with respect to the acceptability constraints, for these indicate the importance of the various acceptability criteria at the margin (i.e., at the point of optimality).

The impacts of marginal increments in acceptability criteria on solar and geothermal utilization are given in Table 6. It is clear that total capital cost is the dominant criterion because the optimal solution is $2-1 / 2$ to 10 times as elastic in response to this acceptability criterion $\cdots:$ it is to cill. viner.

Table 6

ELASTICITY OF SOLAR AND GEOTHERMAL UTILIZATION WITH RESPECT TO ACCEPTABILITY CRITERIA

ACCEPTABILITY

CRITERION

1. Ann. Total System Cost

2. Ann EUD Cost

3. Cost w/o EUD

4. Nonrenewable Resources

5. Environment

6. Total Capital Cost

7. EUD Capital Cost

8. Se1. Env. Costs
ELASTICITY

- - - - - - CONSTRAINT LEVEL - - - - - -

\begin{tabular}{rccccc}
1.04 & 1.06 & 1.08 & 1.10 & 1.12 & 1.14 \\
\hline-- & -- & -- & -- & -- & -- \\
-- & -- & -- & -- & -- & -- \\
8.3 & -- & -- & -- & -- & -- \\
-- & -- & -- & -- & -- & -- \\
-- & -- & -- & -- & -- & -- \\
89.8 & 4.12 & 3.15 & 2.75 & 2.66 & 2.4 \\
-- & .718 & 1.28 & .230 & .239 & .303 \\
57.7 & .230 & .176 & .150 & .144 & --
\end{tabular}

Note: Table entries are given as elasticity =

\% increase in maximum solar and geothermal utilization

\% relaxation of acceptability constraint

for each constraint level.

"--" means zero elasticity (no impact on maximum solar and geothermal utilization). 


\section{Background}

. In the second portion of the study, the analysis is extended 1) to incorporate improved economic and technological parameters into the Brookhaven Energy System Optimization Model (BESOM) and 2) to perform a sensitivity analysis on prices, availabilities of competing technologies and other parameters to see what the effects of such changes are on the implementation levels of the ASGA technologies.

\section{ASGA Technological and Economic Parameter Changes}

The initial task in this second phase of the study was to incorporate into BESOM the most realistic and up-to-date parameters for solar and geothermal technologies. These parameters were provided by the ASGA staff directly involved with the respective technologies. The specific suggestions by ASGA and the BESOM parameter changes associated with them are described in detail in Appendix 1 and summarized below and in Table 7A.

Table 7A

COMPARISON OF REVISED PARAMETERS WITH SF-2 VALUES*

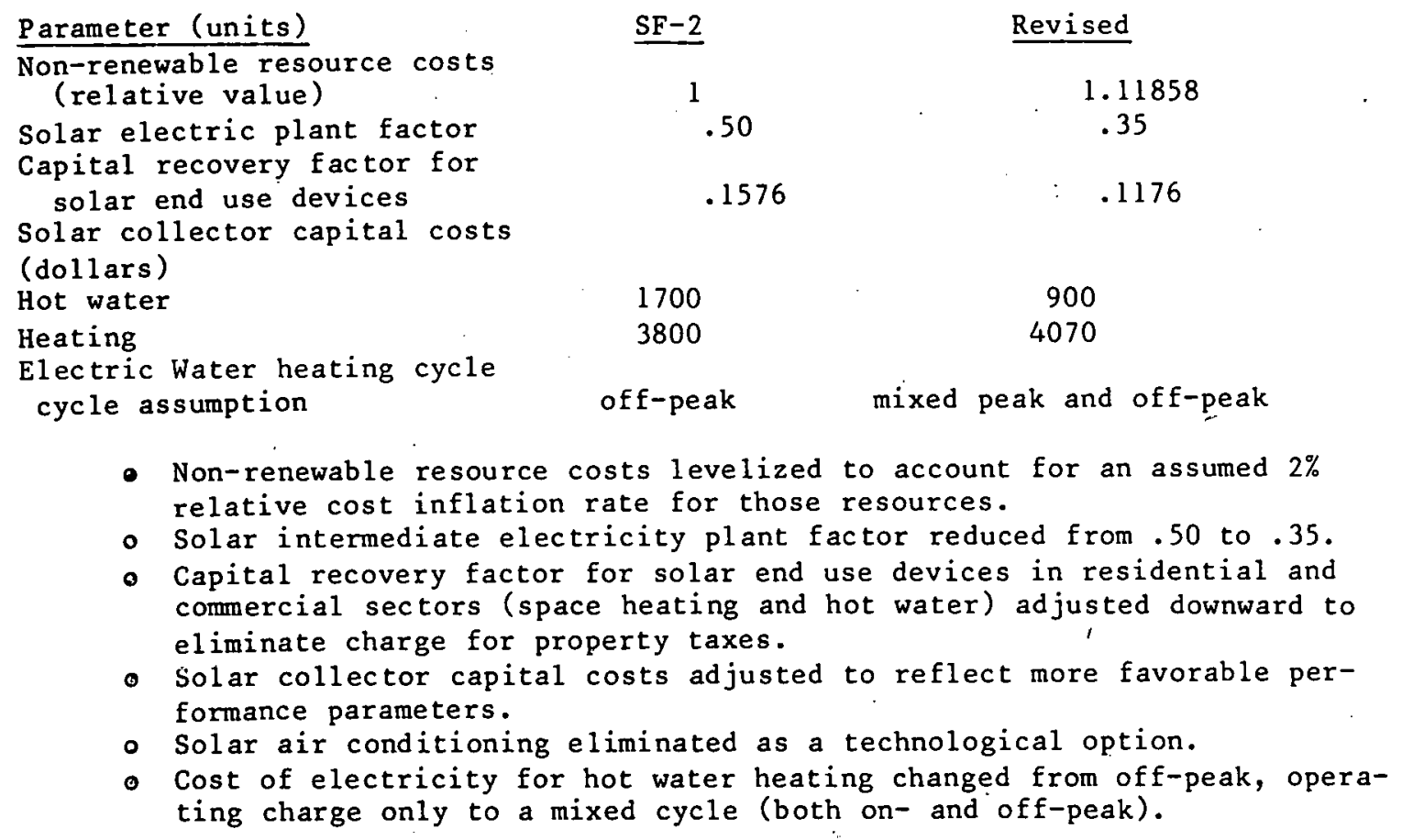

* See text and appendix for more detailed information regarding changes. 
Unless otherwise stated, all of the runs made for this phase of the study incorporated the above changes and also permitted the higher levels of solar and geothermal technologies that were employed in Task 1 as shown on Table 7B.

Table 7B

COMPARISON OF REVISED UPPER BOUNDS ON SOLAR AND GEOTHERMAL TECINOLOGIES WITH SF-2 LEVELS

\section{Technology}

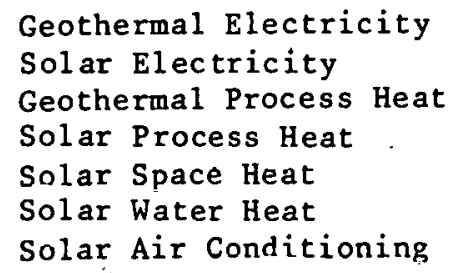

$$
\begin{aligned}
& \text { SF-2 and } \\
& \text { Base Case } \\
& \hline
\end{aligned}
$$

$$
3.00
$$$$
.29
$$$$
.50
$$$$
.34
$$$$
.50
$$$$
.18
$$$$
.09
$$

ASGA

Modifications

$$
\begin{array}{r}
3.00 \\
2.00 \\
1.00 \\
3.00 \\
1.95 \\
.70
\end{array}
$$

$\underline{\text { Results }}$

(a) Effects of Revised Parameters. In order to assess the impacts of the modifications described in the previous section, a series of runs was made as described below:

Base Case: a run with SF-2 economic and technological parameters but with most of the technology utilization levels that were fixed in the later stages of the SF-2 secenario development now left free to vary.*

Revised Bound Case: same as Base Case but higher bounds on solar and geothermal technology implementation levels as employed in Task 1.

Revised Parameter Case: same as the Revised Bound Case but with modifications as described in the previous section.

The results of the above cases are summarized in Table 8 . The Base Case indicates the level of solar and geothermal technologies that competitively enter the solution given $S F-2$ parameter assumptions. As can be seen from the

\footnotetext{
*The "SF-2" case and the "Base Case" used in these runs were slightly different in a few technological implementation levels from the corresponding cases employed in the first part of this study. This reflects the effects of certain improvements in the BESOM technology and economic characterizations that have been made since Part III was completed. These slight changes do not effect the results or conclusions of this report. An additional change made for this task was the elimination of solar air conditioning as a technology option.
} 
table, 1.34 quads of solar and geothermal technology inputs are competitive+ under these assumptions, composed of .5 quads each from geothermal process heat and solar space heat and .34 quads from solar process heat. Each of these technologies is utilized to the maximum extent permitted in SF- 2 .

When higher upper bounds are placed on the solar and geothermal technologies (the Revised Bound Case) the total inputs increase to 2.5 quads table, 1.34 quads of solar and geothermal technology inputs are competitive ${ }^{+}$ comprised of 1.0 quad from geothermal process heat and 1.5 quads from solar these assumptions, composed of .5 quads each from geothermal process heat and solar space heat. No other solar or geothermal technologies are used. Note that the additional .5 quads of the less expensive geothermal process heat displaces the solar process heat and none of the latter is employed in the Revised Bounds Case.

The combined effect of the modifications to both upper bounds and parameters (i.e., the Revised Parameter Case) is that 6.65 quads of solar and geothermal inputs enter the solution. This is nearly 2 quads more than in SF2 and is a substantial 5.31 quad increase over the quantity competitively entering the Base Case. Compared to the Revised Bound Case, geothermal. electricity and solar water heating technologies are utilized in the Revised Parameter Case and, in addition, the utilization levels of solar process heat is now at the maximum level permitted.

The only solar and geothermal technologies not used in the Revised Parameter Case are solar electricity and solar process heat; their use, given the assumptions of this case, is not economically justified.

Changes in important energy system indices in the Revised Parameter Case are also shown in Table 8 . Non-renewable resource use in the Revised Parameter Case is down 7 quads (5\%) from SF-2 levels and the environmental.index drops $5 \%$. The total energy system capital cost increases $7 \%$ and end use device capital cost $9 \%$ due to the greater use of capital intensive solar and geothermal technologies in the Revised Parameter Case. The annualized energy system cost is affected in different ways by the various revisions; levelizing the resource costs tends to increase this index, decreasing the capital costs and eliminating property taxes on solar end-use devices would tend. to decrease it. The net effect of these revisions in the choice of a new optimal combination of technologies (i.e. the Revised Parameter Case) is to increase this index a modest $2 \%$ from the value in SF-2.

Marginal values are computed by BESOM for all technology options the utilization level of which bind against an upper or lower bound in a given run. When the objective function is annualized energy system cost, these values are in units of $\$ / 10^{6}$ BTU and represent the rate of change in the annualized energy system cost with respect to incremental changes in the constraints on the use of the technology. Positive marginal values indicate that more of the technology would be utilized at the margin if available. Negative values indicate that

\footnotetext{
+"Competition" and "optimality" as used in this report refer to technology trade-offs from a macroeconomic national energy system perspective. These concepts are not necessarily consistent with competition and optimality in a. microeconomic sense at specific points in the energy system.
} 
Table 8

COMPARISON OF REVISED PARAMETER CASE WITH SF-2, BASE AND REVISED BOUND CASES

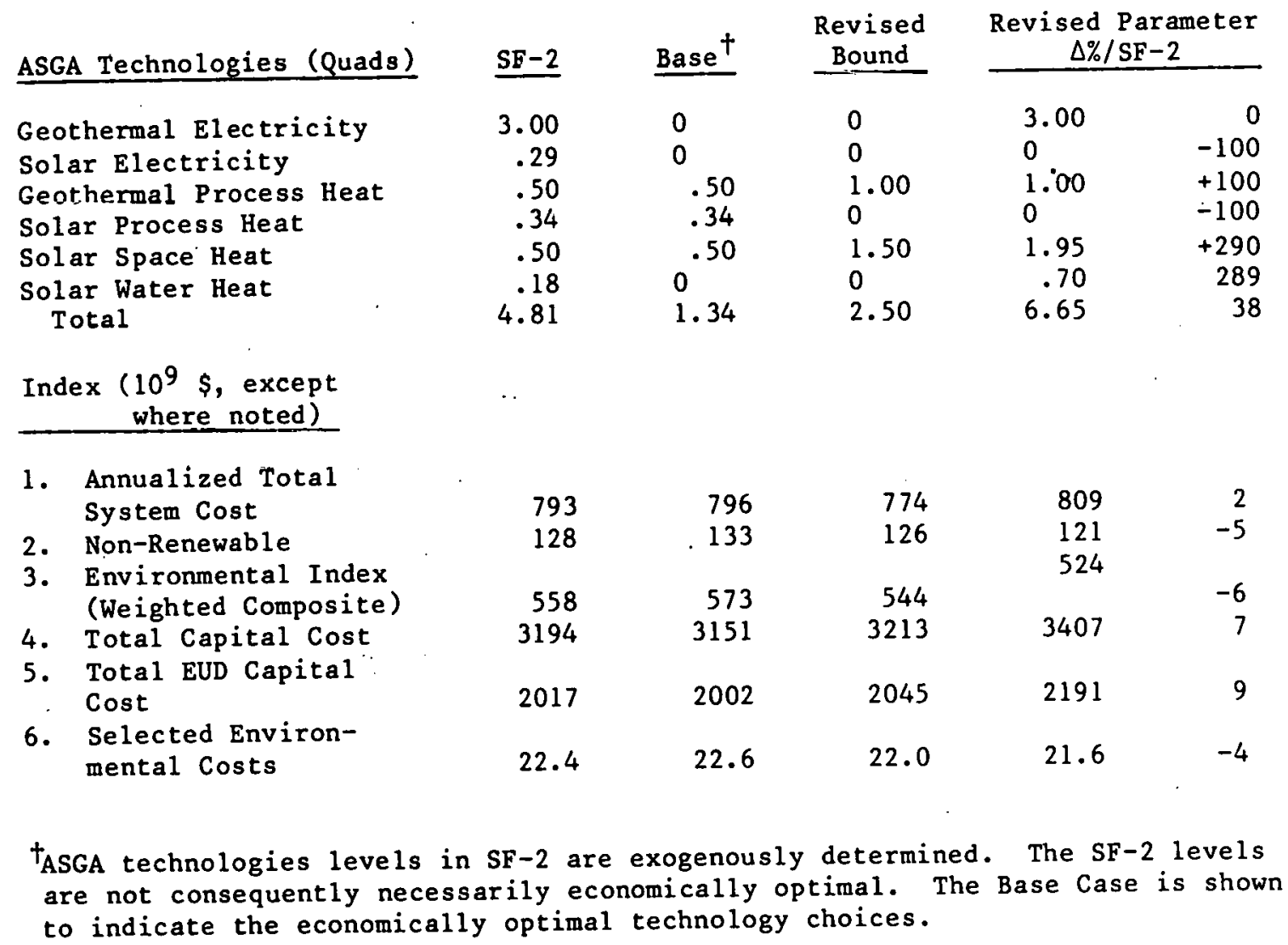

less would be used. If a technology has a lower bound of zero and does not enter the solution, its marginal value is zero. In this case (still assuming that the objective function is a cost measure) the magnitude of the del cost can be interpreted as the subsidy that would be required to make the technology competitive. The marginal values and del costs for solar and geothermal technologies are shown for the Revised Parameter Case in Table 9. Solar process heat is marginally noncompetitive; a cost reduction or a subsidy of $.71 \$ / 10^{6}$ BTU would make this technology competitive. We expect (as is verified in the next section) that relatively small parameter changes should result in some use of this technology. Solar electricity has a larger del cost indicating that relatively larger parameter variations would be required in order for this technology to be utilized. A cost reduction or subsidy of $3.79 \$ / 10^{6}$ BTU would make solar electricity competitive.

It is clear from the above that the alternative parameters developed with the ASGA staff results in substantially greater solar and geothermal technology inputs due to their improved overall economic posture vis a vis other 
Table 9

MARGINAL VALUES AND DEL COSTS FOR SOLAR AND GEOTHERMAL TECHNOLOGIES IN REVISED PARAMETER CASE

\section{Technology}

Geothermal Electricity

Solar Electricity

Geothermal Process Heat

Solar Water Heating

Solar Space Heat

Solar Process Heat
Utilization Leve 1 (Quads)

3.00

0

1.00

.70

1.95

0
Marginal Value (1975\$/106 BTU)

.08

6.24

4.49

3.61
De1 Cost

$-.71$

,

energy system technological options. These increases are accompanied by a lower use of non-renewable resources and a lower environmental index than in SF- 2 . Greater capital expenditures are required, however, to pay for the more capital intensive ASGA technologies.

(b) Parametric Analysis. A sensitivity analysis was performed on the results of the Revised Parameter case in order to determine the robustness of the results with respect to parameter variations that would be expected to affect the competitiveness of solar and geothermal technologies. The following parametric variations about the Revised Parameter Case values were investigated:

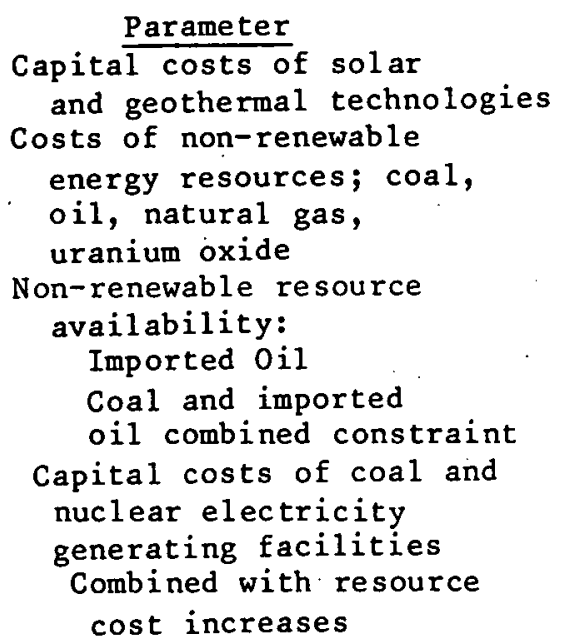

\begin{tabular}{lc}
$\begin{array}{c}\text { Range of Variation } \\
\text { About Revised Parameter } \\
\text { Case Values }\end{array}$ & $\begin{array}{c}\text { Number } \\
\text { of Runs }\end{array}$ \\
\hline$-50 \%$ to $+50 \%$ & 4 \\
$-30 \%+$ to $+150 \%$ & 5 \\
No constraint* to $-30 \%$ & \\
Coal use: 28 gyads \\
Imported: $-30 \%$
\end{tabular}

*Revised Parameter Case employed an upper bound of 21.87 quads on imported oil to ensure that the oil utilization level be consistent with SF-2. The "no constraining" case had no upper bound.

The $-30 \%$ case is not shuwn in Table 10 because the solar and geothermal inputs are identical to the $-15 \%$ case: 
It is important to note that given the bounds on fuel usage in end use applications in $\mathrm{SF}-2$, even small reductions in oil availability produced infeasible solutions. Thus, for those cases in which oil availibility was reduced, greater substitutions away from the use of oil in end-use applications than was permitted in SF-2 were required in order to provide feasible solutions. Allowing these additional substitutions, in essence permitting more rapid capital turnover in the model in response to shortages, is consistent with the assumption that oil availability is reduced. The lower bounds for oil to process heat were changed from 5 to 2 quads, while the upper limit on the use of electricity was increased from .08 to 2 quads for autos and 2 to 4 quads for process heat. (A separate run indicated that the changes in these bounds alone, with no resource constraints, produced no changes in solar and geothermal utilization levels or in the indices.)

Parametric changes that result in increases in non-renewable resource costs, decreases in costs for solar and geothermal technologies, increases in the constraints on the use of non-renewable resources, or increases in the capital costs for coal and nuclear electricity generation, would be expected to increase the ability of solar and geothermal technologies to compete. Compared with the Revised Parameter Case, such changes would tend to improve the competitiveness of solar process heat and solar electricity, the only two solar and geothermal technologies not used in the Revised Parameter Case. Parametric changes opposite to those above would tend to decrease the utilization level of those solar and geothermal technologies employed in the Revised Parameter Case.

The results of the 15 parametric variation cases are compared to SF2 and to the Revised Parameter Case in Tables 10 and 11 . In Table 10, the technology utilization levels for the solar and geothermal technologies are shown for each of the runs along with six indices of economic, energy use, and environmental characteristics of the national energy system. These indices are explained in detail in Part III of this report. In Table 11, selected resource use levels and electricity generation statistics are tabulated for the same set of runs.

The results of the sensitivity analysis can be summarized as follows:

- Geothermal process heat, solar space heat and solar water heat are sufficiently competitive under the assumptions employed in this study that their use in BESOM at the maximum permitted level is unaffected by a wide range of parametric variations. Neither a $50 \%$ increase in the costs of these technologies nor a $30 \%$ decrease in non-renewable resource costs will affect their use.

- The removal of upper bounds on imported oil eliminates all use of solar and geothermal technologies except geothermal process heat. Reducing the availability of imported oil increases the use of these technologies. Thus the availability of imported oil at SF2 prices is a key parameter in determining the economic competitiveness of solar and geothermal technologies.

- The amount of solar process heat used is very sensitive to parameter variations. Although solar process heat is not employed by BESOM in the Revised Parameter Case, increases in non-renewable resource costs, increase in capital costs for coal and nuclear plants, greater constraints on nonrenewable resource and lower costs for solar process heat when applied individually all resulted in some use of this technology. 
Table 10

Effect of Parametric Varlations on Solar and Geothermal Utilization and Energy System Indices

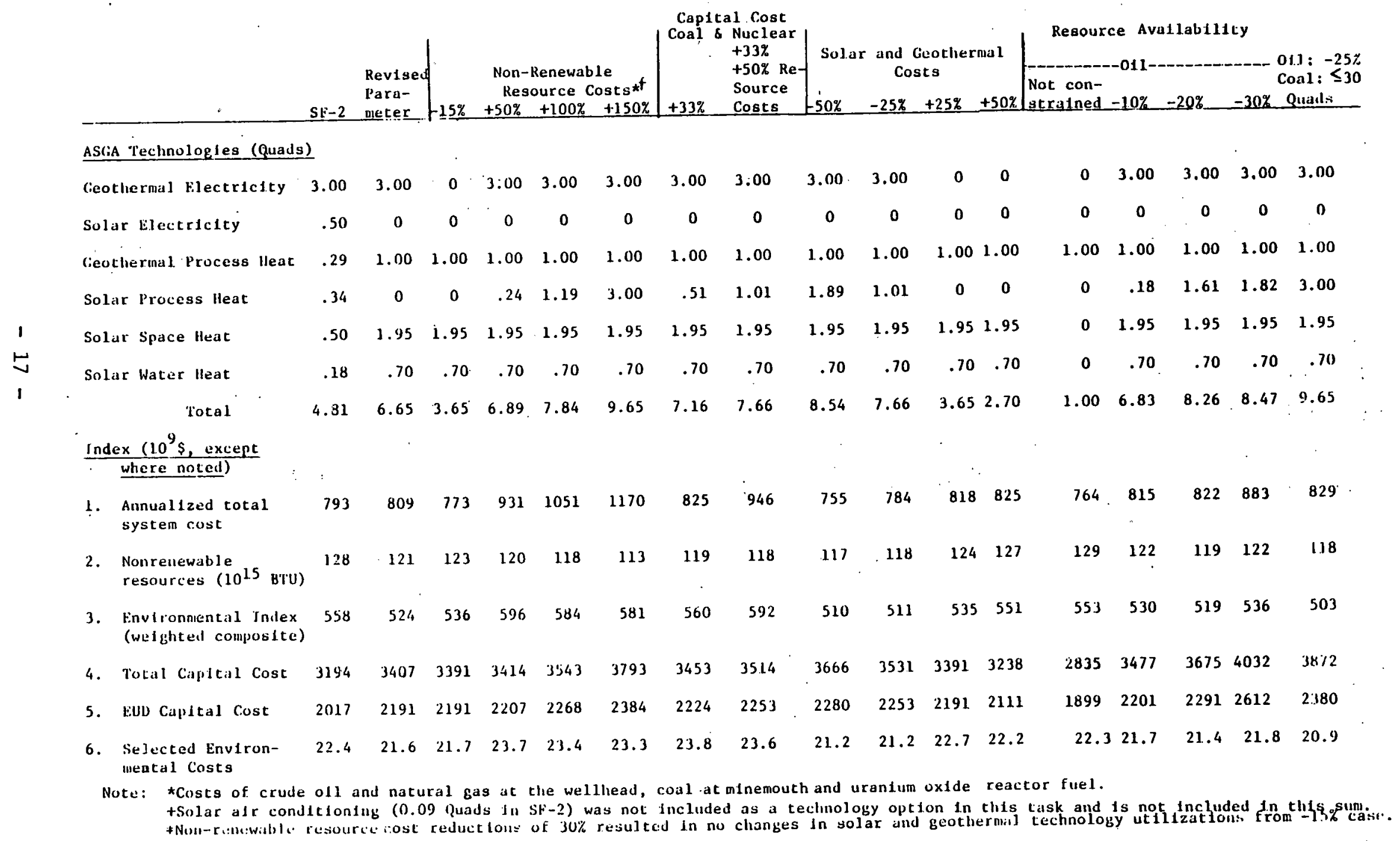


Table 11

Effect of Parametric Variations on Resource Use and Electricity Generation

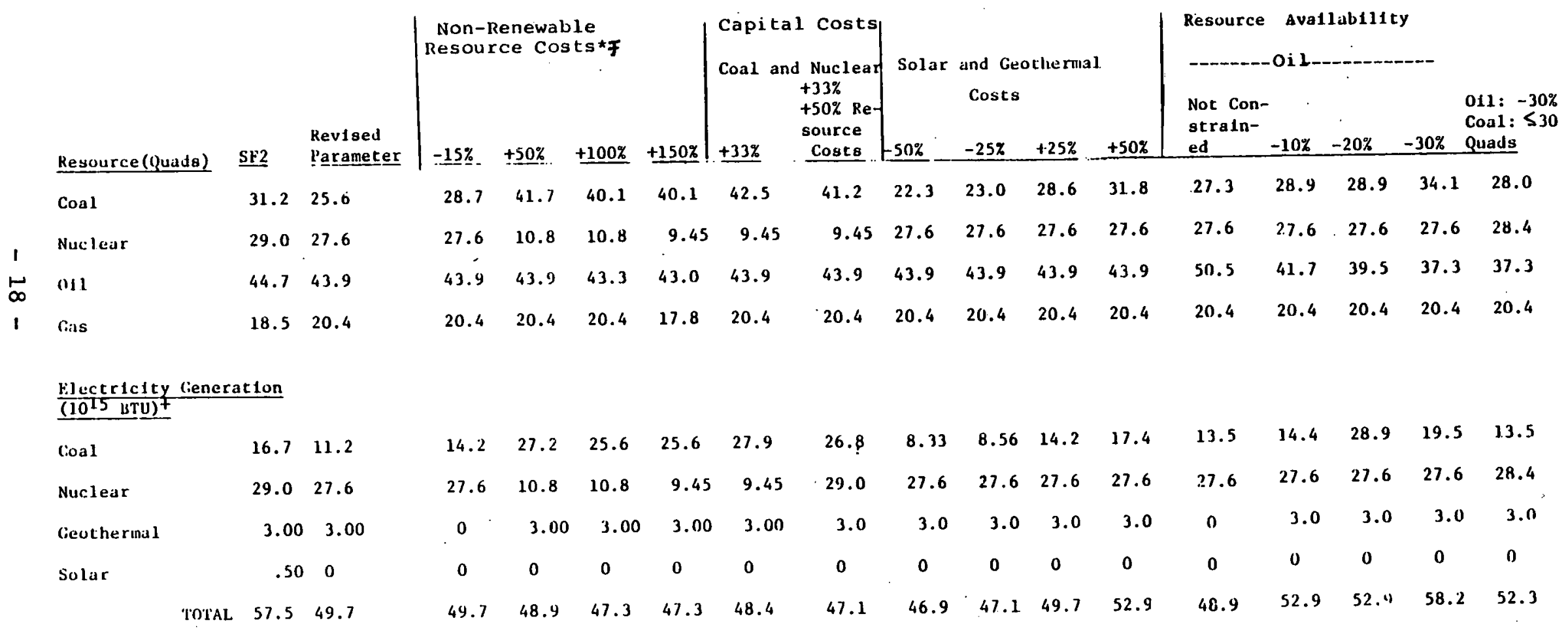

* Costs of crude oll and natural gas at the wellhead, coal at the minemouth and uranium oxide reactor fuel.

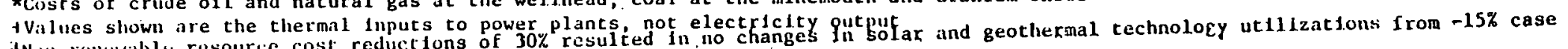

INon-rentewabl. resourice cost reductions of $30 \%$ resulted in, no changes in solar and geother 
- Solar electricity, given the technology characterization employed in this study, was non-competitive. None of the parametric variations resulted in any use of this technology. An additional case (not shown in Tables 10 and 11 ) assuming a solar electric plant factor of .50 (at the same capital cost) and non-renewable resource cost increases of $50 \%$, also did not result in any. use of solar electricity.

- Geothermal electricity is marginally competitive in the Revised Parameter case as is evidenced by the low marginal value shown in Table 9. The parametric runs show that decreases in non-renewable resource costs of $15 \%$, increases in geothermal electricity costs of $25 \%$, and increases in the availability. of imported oil all eliminate the use of this technology.

- The greatest use of solar and geothermal technologies, amounting to 9.65 quads, occurs when either non-renewable resource costs are increased by $150 \%$ or when combined resource constraints are applied. In these cases, only solar electricity of the solar and geothermal technologies considered remains unused. To place resource cost increases of $150 \%$ in perspective, the past five years have witnessed real price increases in imported crude oil, "new" wellhead natural gas, and uranium oxide well in excess of this. Some predictions of the future trend in oil prices place them above this $150 \%$ increase level. Regarding the constraints, 28 quads of coal is approximately double the 1975 usage while the oil constraint level of 15 quads (i.e., the value equivalent to the $-30 \%$ case) is equal to current import levels.

\section{CONCLUSION}

A sensitivity analysis of certain criteria used in constructing national energy scenarios employing an efficient search procedure has revealed that total ASGA technology inputs can be about doubled (increased by about 5 quads) over SF-2 levels with only modest increases in key indices from SF-2 levels. The reasonableness of some of the technology changes associated with the 1 arger increases in ASGA inputs (especially the reduction in nuclear inputs) was beyond the scope of the present study. Substantial increases in ASGA technology contributions are observed even in cases in which changes in key indices and in the technology substitutions from SF-2 scenario levels are essentially zero or negative (i.e., favorable). Except for the most extreme case considered ( 1.04 constraint level case), non-renewable resource consumption declines about $8 \%$ and the requirements for electricity generation decrease from $12 \%$ to $17 \%$ from SF-2 levels as a result of increased ASGA technology utilization. The capital cost constraints employed in this study were the primary limitations on the greater use of ASGA technologies. The long term limitations on capital for investment in ASGA technologies deserve further study.

A review by ASGA of parameters related to solar and geothermal technologies as assumed for the SF-2 scenario for the year 2000 resulted in several modifications to costs, load factors, and capital recovery factors. With these modifications and previous changes to upper bounds on solar and geothermal implementation levels incorporated into the BESOM model, a $40 \%$ increase in solar and geothermal energy inputs was observed over the judgementally determined lev- 
els in SF-2. More significantly, the 6.65 quads level of these inputs in the Revised Parameter Case was substantially greater than the 1.34 quads that was economically optimal under SF-2 assumptions.

In the Revised Parameter Case, non-renewable resource use and an environmental index both drop about 5\% from SF-2 levels. Total energy system capital cost and end-use device capital cost rise $7 \%$ and $9 \%$ over $\mathrm{SF}-2$ values respectively due to the greater use of capital intensive solar and geothermal technologies. The annualized energy system cost increases $2 \%$ over $\mathrm{SF}-2$ levels, the net effect of levelizing resource costs and a new optimum mix at technology options.

An analysis of the sensitivity of the use of solar and geothermal technologies to non-renewable resource costs and availability, solar and geothermal device costs, and the capital costs of nuclear and coal electricity plants indicates:

1) Geothermal process heat, solar space heat and solar water heat are sufficiently competitive under the assumptions in this study that their use is unaffected by a wide range of parameter variations.

2) Geothermal electricity and solar process heat are marginally competitive and marginally non-competitive respectively in the Revised Parameter Case and parametric variations affect the level of their use in the model solution.

3) Solar thermal electric conversion, given the technology characterization employed in this study, was non-competitive.

4) The availability of oil at SF-2 prices is a key parameter in determining the competitiveness of solar and geothermal technologies.

\section{APPENDIX 1}

The SF-2 Scenario

A "surprise free" scenario is one in which energy prices and energy demand grow at moderate rate, major technologies are not prescribed, and actual realized energy resource levels are equal to current resource estimates. Specifically for the SF-2 scenario, the rate of annual increase in oil prices over 1985-2000 period equals 3\% the degree of conservation is moderate, the degree of implementation of new energy supplies is moderate, the rate of annual growth of GNP from 1985 to 2000 is $3.1 \%$, and the total primary energy inputs in 2000 is 139 quads. 


\section{APPENDIX 1 (Cont.'d)}

Prices of. Delivered Energy From ASGA Technologies and Alternative Fuels Employed in SF-2 Scenario For Year 2000

Note: Energy Prices for ASGA technologies and alternative fuels are not comparable in direct applications since the latter do not include EUD efficiencies or capital costs.

Demand Sector and Energy Form (non-electric)

Price $\underline{\left(1976 \$ / 10^{6} \mathrm{BTU}\right)}$

Residential/Commercial

\#2 Fuel Oil

\#6 Fuel oil

Natural Gas

Synthetic Gas

Solar Space Heating

Solar Air Conditioning

Solar Water Heating

3.80

3.43

3.26

4.50

17.12

24.56

23.83

Industrial

Coal

1.07

\#6 Fue1 0il

3.43

Natural Gas

2.62

Synthetic Gas

3.87

Geothermal Process Heat

2.78

Solar Process Heat (Med. Temp.)

10.18

Electricity Generation

Coal Steam

Nuclear (LWR)

Oil Stean

Gas Steam

Geothermal

Solar

\section{Base}

10.15

10.07

16.40

13.60

10.16

13.00
Intermediate

12.35

12.71

18.18

15.25

13.61

17.80
Peak

43.20

49.73

42.65

38.39

61.87

81.70

Resource and Conversion Technology Requirements in SF-2 Scenario in 2000

"*" denotes resource or conversion technology level. that is unchanged throughout all scenarios in the first part of this study (analysis of criteria)

Resource

Coal

Nuclear

* Natural Gas

*oil, Domestic
Amount (Quads)

31.7

29.8

20.4

22.0 


\section{APPENDIX 1 (Cont'd)}

Resource

*0il, Imported
*Shale
*Hydro
Geothermal
Solar

TOTAL

Synthetic Fuels -- Total
Amount (Quads)

21.9

3.0

4.3

3.5

1.4

137.3

0.3

\section{$\underline{\text { Electricity Generation }}^{\dagger}$}

Coal Steam and Comb. Cycle

$1 / .4$

*0il Steam

1.7

Gas Steam

1.8

Gas Turbine

.8

Nuclear

29.0

*Hydro

Total Energy Systems

*Geothermal

4.3

0.3

3.0

Solar

TOTAL

58.2

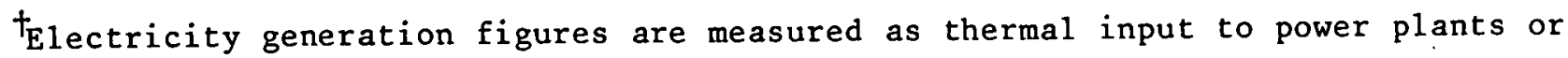
the equivalent for a coal plant.

\section{APPENDIX 2}

The eight indices employed as guides by APAE in developing SF-2 are defined below. of the eight, four (total system cost, non-renewable resources, environmental index and total capital cost) are considered to be of greatest interest.

1) Total System Cost - the total costs for one year for exploration, discovery, extraction, transportation, distribution, energy supply conversion devices and energy end use conversion devices. Capital costs are annualized at a fixed charge rate of $15 \%$ for the appropriate 1 ifetime to yield the capital recovery factor.

2) Annualized End Use Device Cost - the capital cost of end use conversion devices (e.g., furnaces and solar collection systems) annualized at a fixed charge rate of $15 \%$.

3) Annualized Cost Without End Use Devices - total system cost less the annualized cost of end use conversion devices. 
4) Non-renewable resources - total use in 1015 BTU of non-renewable resources at the point of extraction.

5) Environmental Index - an index of weighted residuals. The weights were devised as an average of scores generated by five staff members of BNL's Biomedical and Environmental Assessment Division. The score was assigned to each residual by grading it on a scale from zero to ten as to the seriousness of an additional unit emitted. The residuals included in the index are $\mathrm{CO}_{2}, \mathrm{CO}, \mathrm{NO}_{\mathrm{x}}, \mathrm{SO}_{2}$, particulates, hydrocarbons, bases, nitrates, non-degradable organics, BOd, aldehydes, krypton-85, tritium.

6) Total Capital Cost - this is the invested capital in the energy system including end use devices assuming that the entire energy system had to be replaced with new capital stock without allowances for depreciation.

7) Total End Use Device Capital - this is the total capital investment in end use devices.

8) Selected Environmental Costs - this criterion is the sum of the product of a set of selected residuals and a cost per unit for each. The set of residuals is the same as the set in 6 , preceding, less $\mathrm{CO}_{2}$, krypton-85 and tritium plus dissolved solids and non-degradable organics.

\section{APPENDIX 3}

The Model

BESOM, the Brookhaven Energy System Optimization Mode1, is a normative model using a standard mathematical programing technique called linear programming.* It is structured upon a network description of the U.S. energy system that models flows of energy from resource sectors to end use applications. The variables in the model consist of a set of activities each representing the transformation of an energy resource by one or more energy supply conversion technologies to an end use demand. These activities are measured as flows in units of $10^{15}$ BTU per year. A cost is associated with each activity equal to the sum of the costs of the necessary quantity of the resources required, the annualized capital cost of the supply and end use devices, the operating and maintenance costs of the conversion devices and the transportation, delivery and storage costs.

Additional inputs must be supplied. A set of resource supplies and conversion device capacities are needed. The resource supply constraints are representations of policy variables such as the level of oil imports or energy supply projections such as natural gas availability. The conversion device capacities represent limitations on in place capacity or the level of introduction of new technologies. Also needed is a set of demand requirements expressed in terms of

*A normative model as opposed to a predictive model does not forecast. Instead, it generates the solution that would arise in the long run, governed by the decision structure embedded in the model (in BESOM's case cost minimization under perfect competition) and subject to the uncertainties in the input data and 1 imitations of the relationships modelled. 
energy services. The resource, technologies and demands in the model are shown in the following Table.

RESOURCES

Domestic Crude

Imported Crude

Shale

Surface Coal

Underground Coal

Natural Gas

Uranium

Sun, Wind, Etc.

Geothermal
SOME SUPPLY CONVERSIONS

Electricity Generation

oil, Coal, Gas Turbine

Hydro

LWR, HTGR, LMFBR

Sol ar

Geothermal

Total Energy

Storage

Fuel Cel1s, Pumped, $\mathrm{H}_{2}$

Synthetic

Coal Gasification

other
END USE DEMAND

\author{
Substituteable Electric \\ Base Load \\ Int. Load \\ Peak Load
}

Process Heat

Space Heat

Water lleat

Rail road

Bus, Truck, Water

Private

Air

Feedstocks

Iron \& Steel

Petrochemical

The mathematical structure is to optimize a linear objective function of the form $\pi+\sum_{i}: a_{i} x_{i}$ subject to a set of linear constraints of the form $\sum_{i} b_{i j}$ $\mathrm{X}_{i} \leq \mathrm{C}_{j}$ where $\mathrm{X}_{i} \geq 0$. A typical objective would be to minimize total system cost. Typic constraints would be on:

1) resource supply. These limit the use of each resource to the quantity available.

2) conversion device capacity. These put limits on the conversion of resource to fuels equal to the available conversion capacity.

and 3) demand. These assume that all energy requirements are satisfied.

The model also generates for each solution indices of capital cost, resource utilization, environmental impact, and so forth. For this analysis, some of these indices were utilized as an additional set of constraints specifying that the value attained by a selected index could not exceed by more than a specified percent the absolute minimum value it attained in the derivation of SF-2. Also modeled are daily electricity load duration curves, summer or winter peaks for electricity and the utilization of waste heat.

The model was designed to be used in the technical assessment of new energy technologies. Since any technology can be represented as an activity in the energy network, a new supply technology can be introduced by characterizing it by its fuel input; conversion device efficiency; fuel losses in transport, distribution and storage; costs including fuel costs, annualized capital cost, O\&M cost, transportation, storage and delivery costs; and the end uses that it can supply. End use technologies are introduced in the same way with descriptive data for the end use device supplanting data on the supply conversion technology.

The model was originally used for technology assessment by the Dixie Lee Ray Committee appointed by President Nixon in the aftermath of the 1973 oil embargo. Subsequently it has been used for technology assessment for the national RD\&D plan by. ERDA APAE. APAE has also used it as the process model component of the combined Brookhaven linear programing-input/output model which has been 
married to the Hudson-Jorgenson model to provide the economic input to the ERDA RD\&D plan.

A feature of this type of model is the wealth of information that is provided; 1) on cost reductions which will bring technologies that are not in the solution into it; 2) about higher costs that will drive technologies currently in the solution out and; 3 ) on the value (in terms of decreasing the total system cost) of relaxing any binding constraint. Hence, one can examine cost uncertainties, supply uncertainties, anticipated capacity goals, and demand expansion or contraction. A major strength of the model in analyzing new technologies is the information provided on the substitution of one fuel for. another. 
APPENDIX 4

VALUES OF INDICES IN MINIMIZATION RUNS

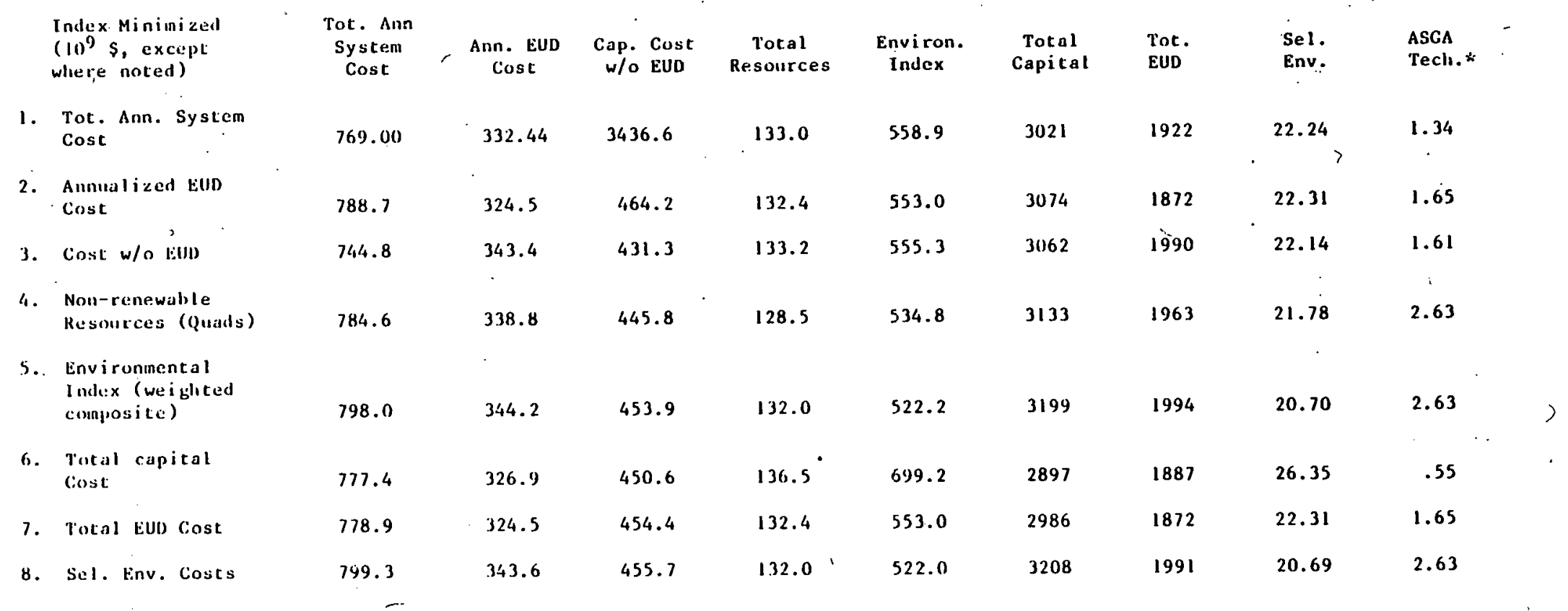

WNot an inilex, shown for referenc: only. 


\section{APPENDIX 5}

Changes from SF-2 to ASGA Runs

Several changes were made in the BESOM equations for the ASGA runs from the equations employed in the final run of $\mathrm{SF}-2 . *$ These changes, were needed since SF-2 exogenously specified the level of contribution from the solar and geothermal technologies while for the ASGA runs, these contributions were to be determined endogenously (subject to an upper limit). The following limiting equations were therefore changed from equalities in SF-2 to upper bounds in the ASGA runs:

Direct Solar and geothermal constraints:

Limit solar to space heat

Limit solar to process heat

Limit solar water heating

Limit solar to air conditioning

Indirect constraints on solar and geothermal:

Constrain electric space heat

Limit electricity to heat pump

Limit electricity to process heat

Limit amount of electric water heating

Gas to water heat

In addition, certain constraints on supply conversion technologies were changed from equalities to upper bounds:

LWR Inputs

LMFBR Inputs

HTGR Inputs

Geothermal Resource Inputs

Solar Electric Inputs

GNP from Coal Inputs

Finally, it was necessary to fix the level of oil imports to the SF-2

usage level of 21-9 quads to prevent the model from creating solutions which used unreasonable levels of imported oil.

\section{APPENDIX 6}

1. Comment: a) Inflation rate for capital should be the same as the general rate of inflation and the inflation rate for fuel should be $2 \%$ over general inflation.

b) Fuel prices should be levelized over lifetimes of systems. BESOM Parameter Changes: Levelizing of prices was applied to resources; i.e., energy at the minemouth for coal, wellhead for oil and gas and to $\mathrm{U}_{3}$ $0_{8}$ ) for nuclear. For $2 \%$ relative inflation rate levelizing is equivalent to increasing all resource costs by about $12 \%$ if the 1 ifetime of all equipment is assumed to be 20 years. The fuels used to produce electricity generated from non-renewable resources were thus affected while the cost of electricity generated from renewable resources remains unaffected.

*The version of $\mathrm{SF}-2$ available for this study for comparison purposed was a March 20, 1977 version (cycle 非13). 
2. Comment: The utilization factor for solar intermediate load electricity should be 0.35 instead of 0.5 . BESOM Parameter Change: As stated.

3. Comment: Assume no property tax expense for solar residential and commercial end use devices.

BESOM Parameter Change: The capital recovery factor for solar end use devices in the residential and commercial sectors (space heating and hot water) was reduced from 0.1576 to 0.1176 .

4. Comment: For solar hot water systems, assume $7 \mathrm{f} 2 / 10^{6}$ BTU (not mure than $8 \mathrm{f}^{2 / 10} 6 \mathrm{BTU} /$ year) with solar providing $80 \%$ of the total heat load, and for solar space heat assume $10 \mathrm{f}^{2} / 10^{6} \mathrm{BTU} /$ year with solar providing $60 \%$ of the total head load.

BESOM Parameter Changes: The net result of the above performance parameters (using the $7 \mathrm{f}^{2 / 10^{6}} \mathrm{BTU} /$ year and $10 \mathrm{f}^{2} / 10^{6} \mathrm{BTU} /$ year figures respectively for hot water and space heat) is to change the cost of solar systems as shown below:

\section{Capital Cost of Solar Residential and Commerical Systems}

$$
\text { (constant } 1975 \text { \$) }
$$

Year

1985

1990

2000

$$
\text { Water Heating }
$$

$\$ 1130$

1050

900
Space Heating

$\$ 5230$

4800

4070

The fraction of energy provided by solar for space heating was $60 \%$ in the model, the fraction for water heating was left at the $90 \%$ previously in the model. The assumed costs per square foot for collectors $\left(\$ 14.75 / \mathrm{f}^{2}\right.$ for $1985, \$ 13.50 / \mathrm{f}^{2}$ for 1990 and $\$ 11.40 / \mathrm{f}^{2}$ for 2000$)$ were not changed.

5. Comment: Eliminate solar cooling as a technological option. BESOM Parameter Change: As stated.

6. Comment: The cost of electricity for electric hot water heating, a competitor of solar water heating in the model, is artificially low as it includes only the fuel charges used to produce off-peak electricity. This is based on the unrealistic assumption that only off-peak electricity is employed to heat domestic hot water and that the cost of such electricity need not include plant capital amortization costs. This cost should be changed so that the electricity for water heating is charged for capital amortization and so that its cycle load is weighted toward the daytime. BESOM Parameter Change: Change electricity for hot water heating the full cost of generation and transmission and change its daily cycle load. 
120

$$
2 A N / 2418-1
$$

120

480 